PHYSICAL FACILITIES

The primary equipment for the laboratory is a Xerox Data Systems Sigma 3 computer. This is a sophisticated process-control computer. The system architecture is defined around eight hardware registers with a sophisticated set of register-to-register, memory-to-register, and register-to-memory transfer instructions. The memory (16-bit words) is multiported to accommodate to the multiprocessor configuration of the basic system, involving independent (parallel) I/O processing and CPU processing. Current memory is composed of $40 \mathrm{~K}$ words, arranged in three blocks of memory, each block ported both to the $I / O$ processor and to the CPU. Memory is expandable to $65 \mathrm{~K}$, with a maximum of four blocks, each with four ports. Memory is functionally partitioned into foreground and background, with real-time processing in foreground protected by programmable hardware memory-protection registers. The real-time hardware priority-interrupt system includes up to 100 external interrupt levels. Four real-time clocks are installed on the computer. A wide range of peripheral equipment has been installed: 200-cpm card reader, 225-1pm line printer, 7-track 20-kc magnetic tape, 3 million character disk (fixed head, $17 \mathrm{msec}$ average access, $170-\mathrm{kc}$ transfer rate), 49 million character-disk pack drive (dual spindle, $87 \mathrm{msec}$ average access, $312 \mathrm{kc}$ transfer rate). Special systems equipment installed on the computer include 72 discrete input and output lines and eight communications lines operating at a variety of baud rates. Future expansion will fill out allowed memory, add a large number of discrete I/O lines, add two 9,600-baud lines, 28 additional slow-speed lines, and a 48,000-baud line linked to the University of Colorado CDC 6400 . Terminal equipment now installed includes six Teletype machines (two Model 33KSRs, four Model 37KSRs), two UNIVAC Uniscope 100 keyboard/displays (character oriented), and an XDS character-oriented keyboard/display. Future expansion of terminals will be in the area of keyboard/display equipment and graphics displays. The laboratory is working with the Department of Electrical Engineering on campus to develop a graphics controller capability for the Minuteman I D-17 computers the two departments own.

\section{PERSONNEL}

At the time the laboratory was established, 12 of the Department of Psychology faculty (more than one-fourth of the faculty) participated in the planning. Additional faculty members have become active in the laboratory. Not all of the original group have brought their research and training activities onto the laboratory facilities. However, as the laboratory facilities are filled out and at such time as the laboratory is in permanent quarters in a new wing of the Psychology Building, I anticipate that as much as $50 \%$ of the faculty will be active in one or another aspect of the project.

An extremely important aspect of the operation of the laboratory is the professional technical staff. Because of the magnitude of the project and the ambitious plans for software development, the professional systems programmers on the staff are pivotal in the laboratory. Currently there are three full-time systems programmers in the laboratory. In addition, the laboratory is developing hardware interfaces for laboratory instruments. This development and certain maintenance functions in the laboratory are performed by the fourth full-time professional technical staff member, an electronics engineer. Two clerical staff members and four graduate-student research assistants fill out the staff roster.

\section{REFERENCE}

BAILEY, D. E. The Computer Laboratory for Instruction in Psychological Research: An introduction to the laboratory. Publication No. 1, January 1970, CLIPR Publication Series, University of Colorado, Boulder.

\title{
Training mathematical psychology students in the use of a laboratory computer
}

\author{
FRANK M. GOODE \\ University of Michigan, Ann Arbor, Michigan 48104
}

About 4 years ago, the Mathematical Psychology Laboratory at the University of Michigan obtained a laboratory computer in order to give our mathematical psychology graduate students some experience in the use of on-line computers.

We have a LINC-8 with its standard features: $4 \mathrm{~K}$ memory, analog-to-digital converter inputs, binary inputs, relay controls, an ASR-33 Teletype, two magnetic-tape units, and a cathode-ray tube (CRT). As additional features, we have a clock, an ASR-35 Teletype, a high-speed reader and punch, a duplicate CRT, and a light pen. The extra CRT is used to display stimuli to experimental $\mathrm{Ss}$ in an adjoining room. It is connected by cable to the console CRT and basically displays the same thing as the console CRT (although by selecting different channels on the two scopes, it is possible to obtain different displays).

Keith Smith had primary responsibility for selecting this configuration for our laboratory. He now says that with the advantage of hindsight, he would change one or two components. However, I think that, in the main, his choice was clearly the best that was available at the time. I am not prepared to say what the best would be today, but I think that the criteria he used are still applicable. Within the given budget limits, his major criterion was that of versatility. We wanted to use the computer mainly for training rather than for any specific research application. The students would use the computer in their research, but we did not want to restrict unduly the types of research that they could do. Smith therefore looked for a versatile computer with a variety of features so that students would be relatively free to dream up a wide range of research applications.

He recommended the LINC-8 made by Digital Equipment Corporation, and it has worked out extremely well. The students have been very imaginative in their use of the computer. In addition to their being able to do better research, we have discovered another valuable benefit-namely, their learning from each other. During the various stages of their research, and particularly while setting up an experiment, students interact a lot with each other. As a result, each student's research experience is virtually multiplied by the number of other students that he talks to, particularly if there is much variety in their research.

The thing that has been most common to their research has been the use of the CRT to display visual stimuli to human Ss. We have displayed points, lines, figures, dot matrices, and spinner-board pictures, as well as numerals, letters, syllables, words, phrases, and sentences. These displays have been used to study learning, memory, cognition, perception, impression formation, information processing, signal detection, problem solving, decision making, and measurement theory. Figure 1 shows two photographs of an S's display on the CRT. The S's task in 

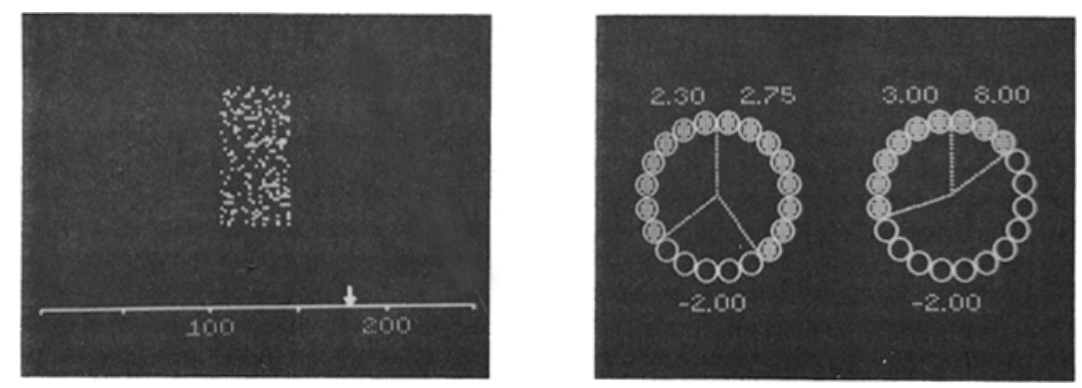

Fig. 1. Photographs of the CRT showing samples of psychological stimuli in (a) measurement-theory and (b) a decision-theory study.

the measurement-theory study shown in Fig. 1a is to adjust the moving arrow along the scale (by turning a potientiometer knob) according to his magnitude estimation of the number of dots in the array. The S's task in the decision-theory study shown in Fig. 1b is to choose which of the two gambles he would most prefer to play. This latter display closely simulates the actual spinner boards used during the training session.

Only three studies have not used the CRT to display visual stimuli to human Ss. One was an animal study by an expeximental psychology student (Timberlake, 1969) carried out before our computer was moved to its current location, where we no longer have animal facilities. Another experiment was an auditory study by Jane Siegel (1971) investigating the phenomenon of perfect pitch. She obtained auditory stimuli from a Wavetek tone generator which produces tones that vary as a function of a voltage input. For the computer to control the tone generator, Siegel needed a digital-to-analog conversion, and this was available from the cable connection to the duplicate CRT. Among the various signals in this connection are two continuous voltages corresponding to the $x$ and $y$ coordinates of the point being displayed, so she merely substituted a special cable going to the Wavetek tone generator.

The third study was an eye-movement experiment by Russo (1971), using a software package developed by Goode and Russo (1970). The CRT was used in this study, but not as a $\mathrm{S}$ display; his stimuli were projected onto a wall screen. The CRT displays were used by the $E$ to monitor the S's eye movements. The in put signals for this study were two voltages that varied continuously according to the horizontal and vertical movements of the eye; these were fed into the analog-to-digital converter lines.
Due to the research interests of most of our students, discrete responses (usually binary) that can be collected by means of pushbutton switches have usually been adequate. Such responses can also be collected from the Teletype keyboard, but, when the response alternatives are limited, it is usually preferable to use a pushbutton response box with the appropriate number of alternatives (clearly labeled). We have had only one study that used the Teletype keyboard for the S's response, and that was an experiment in which it was important to maximize the number of response alternatives and minimize the response cues.

We feel that we have been very successful in getting our students actively involved with our laboratory computer. We have a regular class each fall which the beginning mathematical psychology graduate students are expected to take. Many of them make prompt use of the computer for the small research study that they are required to carry out their first year. Some of them do not find the computer appropriate for their particular study, but there are students from other areas of psychology that do. Many of our students use the computer for both their first-year study and their thesis research.

Our class has one 2-h session per week, and the students spend additional time outside of class writing and debugging programs. The first week is devoted to the interpretive language FOCAL, which is easy to learn and convenient for small statistical and mathematical problems. We next demonstrate various experimental programs that previous students have used, and the rest of the term is devoted to learning the LINC system, using the LAP-6 Assembly language. I organize the material so that we start using the computer immediately, and everything builds on what was previously learned. I believe that two basic principles in teaching the use of a computer are that examples are vital in transmitting information and that practice is vital in assimilating the information. I therefore emphasize examples and exercises rather than formal study. I have also used this approach effectively in three other computer courses that I teach.

One of these is the computer training that we have offered to the participants in our "Summer Institute in Mathematical Psychology for Psychology Teachers in Colleges and Universities." We usually teach the PDP.8 rather than the LINC to this group, since it is easier to learn and more of the participants are likely to have access to a PDP- 8 than a LINC or its successors.

Earlier in the conference, Uttal said something to the effect that if one had the choice between buying a configuration of special-purpose components for a given research application or buying a small general-purpose computer in place of most or all of the special-purpose components, it is usually much better to get the general-purpose computer. His reasons were mainly in terms of ultimate advantages to the researcher. I think there is another reason that underscores his conclusion even more strongly, and that is the consideration of training. Most psychologists using on-line computers in their research are doing so in an educational setting, and, as such, the training of their students may be as important (or more so) than the immediate research goals. If it is at all possible to give students the opportunity to learn something about the potential of on-line computers in research, then we should make every effort to do so. The role of large computers for data analysis, etc., is well established in psychology today; but an understanding of the use of small on-line computers is still in the developmental stage. Most of us do not fully comprehend the potential of on-line computers in psychological research; but we can be sure that our students will discover innumerable applications that have not occurred to us. However, we must first provide them with the tools.

$$
\text { REFERENCES }
$$

GOODE, F. M., \& RUSSO, J. E. Computerized system for collecting eye movement data. Proceedings, 78 th Annual Convention, APA, 1970.

RUSSO, J. E. The multi-alternative choice process as tracked by recording eye fixations. Unpublished doctoral dissertation, University of Michigan. 1971.

SIEGEL, J. A. The nature of absolute pitch. Unpublished doctoral dissertation, University of Michigan, 1971.

TIMBERLAKE, W. D. Continuance coding of general activity in the rat during repeated exposure to a constant environment and to stimulus change. Unpublished doctoral dissertation, University of Michigan, 1969. 